\title{
Heavy Metals Capture from Water Sludge by Kenaf Fibre Activated Carbon in Batch Adsorption
}

\author{
Anwar Ameen Hezam Saeed ${ }^{1}$, Noorfidza Yub Harun ${ }^{1 *}$, Neisha Zulfani ${ }^{1}$ \\ ${ }^{1}$ Department of Chemical Engineering, Universiti Teknologi PETRONAS, 32610 Bandar Seri Iskandar, Perak, \\ Malaysia \\ * Corresponding author's e-mail: noorfidza.yub@utp.edu.my
}

\begin{abstract}
The Malaysia's wastewater treatment plant has yet to find an environmentally alternative for the sludge treatment before disposal. In majority of cases, the sludge containing a high amount of heavy metals including $\mathrm{Fe}, \mathrm{Ti}, \mathrm{Mn}$, $\mathrm{Zn}, \mathrm{As}, \mathrm{Cu}, \mathrm{Ni}, \mathrm{Zr}$, and $\mathrm{Ga}$, is disposed to the environment through landfill. The recovery of valuable materials such as manganese from the sludge is an alternative path towards zero dumpings of schedule waste as well as a way of reducing the possible pollutant release to the environment. It can be achieved through adsorption, as it provides a cheap yet flexible, method which is simple and easy to implement. Kenaf derived from Hibiscus cannabis was proven as a good adsorbent material for the heavy metals recovery. This project aims at utilizing Kenaf fiber as activated carbon to recover heavy metals from wastewater sludge in batch adsorption. The adsorbent surface area and pore characteristics and elemental analysis were observed under adsorbent characterization. The effect of contact time, sludge $\mathrm{pH}$ and temperature to the removal efficiency was investigated. The adsorption isotherm was also studied. The result showed that the developed kenaf activated carbon is a promising adsorbent which might be used for some heavy metals. From batch adsorption study, it was observed that KFAC is able to remove an average $30 \%$ of the heavy metal element from the sludge. It was also found that the best removal is achieved in a neutral $\mathrm{pH}$ solution, increasing the contact time will increase the equilibrium uptake, while the increasing temperature will increase the percent removal of heavy metals. It was concluded that the Kenaf based activated carbon can be used for the recovery of heavy metals from the wastewater sludge through batch adsorption.
\end{abstract}

Keywords: Kenaf fiber, activated carbon, sludge, heavy metals, batch adsorption, water treatment

\section{INTRODUCTION}

Aiming towards zero discharge of residuals from water treatment has been targeted for decades. However, the chemical and biological treatments, which contribute to the discharge of sludge problems, cannot be avoided for safe and clean water. The sludge produced, containing high amounts of contaminants, is another thing to concern before discharging it to the environment. The recovery of valuable materials from the sludge is an alternative path towards zero dumpings of schedule waste as well as a way of reducing the possible pollutant release to the environment. In the majority of cases connected to the Malaysia sewage management, the sludge containing a high amount of heavy metals is disposed of to the environment through landfill.
At a certain level, the accumulated amount of heavy metals being disposed of can cause an undesired effect on the environment. The current sludge management available includes the disposal without treatment, disposal after treatment as well as utilization and reuse of nutrients $\&$ recyclables with or without treatment. In Malaysia, the majority of research has been done on the heavy metals capture from wastewater. However, the research on the recovery of heavy metals particularly in the wastewater sludge has yet to be done intensively; hence, most of the time, the heavy metals contained in the sludge obtained from wastewater treatment plants are disposed of either in a sanitary landfill or through incineration.

The recovery of manganese and other heavy metals from the sludge can be achieved through 
adsorption, as it provides a cheap yet flexible method, which is simple and easy to implement. Adsorption is a conventional technology that has been used for decades and is proven to be efficient in removing heavy metals from water. The removal of heavy metals from the water treatment sludge can be done either in batch or through a fixed-bed adsorption column. The batch adsorption offers heavy metals removal in a batch, whereas the fixed bed column offers a continuous removal through the adsorption and desorption process done repeatedly. The efficiency of both adsorption methods is dependent on the area where they are applied, adsorbent characteristics and the operating conditions.

Several adsorbents have been developed from different materials to enhance the adsorption performance while significantly reducing the cost and being environmentally friendly and sustainable. Natural materials and certain industrial wastes have the potential to be used as a low-cost adsorbent, for instance, agricultural wastes that are usually porous, lightweight and have carbox$\mathrm{yl}$ as well as hydroxyl functional group on their surface, are suitable for use as adsorbent [Chowdhury 2013]. However, the applicability of these materials is restricted up to a certain limit, associated with their small surface area and leaching of some organic substances into the aqueous solution; hence, these residues can be converted to activated adsorbent either by producing activated carbon or by simple chemical treatment to enhance the surface area [Saravanane et al. 2002].

The use of Kenaf as a heavy metal adsorbent has been started recently. Kenaf is derived from the core of the Hibiscus cannabinus fiber. Kenaf based activated carbon has been proven suitable for the removal of various heavy metals from aqueous solutions. Intensive studies on its capability to recover manganese from wastewater while offering cheap and environmentallyfriendly solutions have conducted for the past few years. Hasfalina et al. reported that Kenaf showed a good capacity for removing heavy metals from aqueous solutions in batch studies [Hasfalina et al. 2010]. Later research by Hasfalina et al. claimed that Kenaf also has good potential to be used in the adsorption of heavy metals from aqueous solution in a fixed bed column [Hasfalina et al. 2012].

Adsorption is the process of retaining atoms, molecules or ions of dissolved solids, liquids or gases on the surface having certain active sites. It utilizes the concept that substances have a different affinity to a solid (adsorbent) to separate them. Adsorption can be classified into two types, i.e. physical and chemical adsorption. The physical adsorption is a reversible process which involves weak forces of van der walls, hydrogen bonding and dipole-dipole interactions between the sorbent and sorbate while the chemical adsorption is an irreversible process that occurs at high temperature and involves exchange or sharing of electrons between the sorbate and sorbent.

The factors affecting adsorption include temperature, $\mathrm{pH}$, nature of adsorbate or adsorbent and surface functional group, liquid phase concentration and many more. The reverse process is called desorption. Desorption is the process in which the solute is released back from or through the surface. In an equilibrium system, adsorption and desorption occur simultaneously, depending on the concentration gradient between the bulk phase and the surface of the adsorbent. When equal amounts of solute adsorb and desorb simultaneously, the system attains an equilibrium state which is called adsorption equilibrium.

When the system reaches equilibrium, there is no further net adsorption. The amount of solute adsorbed per unit weight of adsorbent is denoted by $q_{e}$ while $C_{e}$ is the amount of solute failed to attach onto the surface of the sorbent, hence remain in the solution phase. The equilibrium uptake is calculated using Eq. 1.

$$
q_{e}=\frac{C_{e} \cdot V}{m}
$$

where: $q_{e}$ is adsorption capacity $(\mathrm{mg} / \mathrm{g})$,

$C_{e}$ is the difference between initial concentration and concentration at the time $t$ $(\mathrm{mg} / \mathrm{l})$,

$V$ is the volume of solution in a litter, $m$ is the mass of the adsorbent in gram.

\section{MATERIALS AND METHODS}

\section{Adsorbent preparation}

For the adsorbent preparation, the main material used is Kenaf fiber which obtained from the Malaysian Agricultural Research \& Development Institute. The steps undertaken for adsorbent preparation include grinding of the Kenaf fiber, sieving to the size of 1-2 $\mathrm{mm}$, washing in deionized water and drying under $105{ }^{\circ} \mathrm{C}$. The dried precursors were stored in the desiccator to prevent 
the moisture build-up and fungi contamination. Pyrolysis was performed by taking approximately 10 to $15 \mathrm{~g}$ of precursors, which were placed on the metal mesh at the bottom of the reactor while inert gas nitrogen was purged at a flowrate of $150 \mathrm{~cm}^{3} / \mathrm{min}$ from $250{ }^{\circ} \mathrm{C}$ to $400{ }^{\circ} \mathrm{C}$ at a rate of $100^{\circ} \mathrm{C} / \mathrm{min}$ and held isothermally for two hours. The chars produced could cool down before storing it with the desiccator. The chars were impregnated with $\mathrm{KOH}$ at a ratio of 1.74 . The ratio was calculated from the formula:

$$
I R=W_{K O H} / W_{\text {char }}
$$

Where $\mathrm{W}_{\mathrm{KOH}}$ was the weight of $\mathrm{KOH}$ and $\mathrm{W}_{\text {CHAR }}$ was the weight of char obtained from pyrolysis. Using the formula and the ratio given, $40 \mathrm{~g}$ of char and $69.6 \mathrm{~g}$ of $\mathrm{KOH}$ were mixed with $500 \mathrm{ml}$ DI water. The mixture was stirred until $\mathrm{KOH}$ was completely dissolved. The solution was heated until some of the water evaporated before drying it up overnight in the oven at temperature $105^{\circ} \mathrm{C}$ leaving only $\mathrm{KOH}$.

The sample was placed inside the stainlesssteel tubular reactor while inert gas nitrogen was purged at a flowrate of $150 \mathrm{~cm}^{3} / \mathrm{min}$ from $25^{\circ} \mathrm{C}$ to $584.27^{\circ} \mathrm{C}$ (activation temperature) at a rate of $10^{\circ} \mathrm{C} / \mathrm{min}$. Once the activation temperature was reached, nitrogen gas was switched to carbon dioxide having the same flowrate to initiate the activation. The process was then held isothermally for 1.68 hours. The activated sample could cool down before washing to remove the unreacted $\mathrm{KOH}$. The activated samples were washed using deionized water and a little drop of $0.1 \mathrm{M} \mathrm{HCl}$ to condition the washing $\mathrm{pH}$ within 6-7. The washed samples were dried in the oven at $105^{\circ} \mathrm{C}$ until it was completely dried. The washed samples of activated carbon were dried at $10^{\circ} \mathrm{C}$ in an oven until completely dried. They were stored in an air-tight container for the adsorption study.

\section{Adsorbate preparation}

The raw material used in this study is the sludge from Sungai Selangor Phase 2 (SSP2) Water Treatment Plant. It is considered secondary sludge containing some of the heavy metal which becomes contaminated by treating polymers and alums during coagulation and flocculation process. The sludge was subjected to characterization to determine the amount of heavy metal in it. Then, the sludge sample was dried in the oven at $105^{\circ} \mathrm{C}$ for 1 day. The dried sludge was stored in a few containers and labeled accordingly. The sludge sample was collected at every time interval into a $3 \mathrm{ml}$ glass bottle for further measuring of heavy metals concentration using X-Ray Fluorescence (XRF). The $500 \mathrm{ml}$ sample were placed in few beakers.

\section{Adsorbent characterization}

The adsorbent characterization was performed to investigate the bulk density, iodine number, surface area, and pores as well as surface morphology of the prepared activated carbon.

\section{SAP characterization}

Surface area, pore diameter, and pore volume were measured by using a surface area analyzer and porosimeter system model Micromeritics ASAP 2020. Approximately 0.1g KFAC was used for the analysis.

\section{Morphological and elemental analysis}

Surface morphology and elemental qualitative analysis of the Kenaf precursors, semi carbonized char, KFAC before and after adsorption was carried out using Field Emission Scanning Electron Microscope (FESEM) model VPFESEM Zeiss Supra55 VP. The elemental quantitative analysis of KF, KFC, KFAC before and after adsorption was carried out using X-Ray Fluorescence.

\section{Batch adsorption preparation}

In this section, the effect of temperature, $\mathrm{pH}$, agitation speed and contact time to the percent removal of heavy metals from the sludge was studied. Uniform adsorbent mass for each experiment was used at $500 \mathrm{mg}$ and the volume of sludge solution was $100 \mathrm{ml}$.

\section{Effect of contact time}

In order to study the effect of contact time on the adsorption process, the temperature during adsorption was set to $30^{\circ} \mathrm{C}$. Hence, a temperature control water bath stirrer was used. The solution $\mathrm{pH}$ was set to 7.28 , stirring speed $50 \mathrm{rpm}$, and initial adsorbate concentration was the one measured under sludge initial condition by XRF. The sludge concentration was about $2000 \mathrm{mg} \cdot \mathrm{L}^{-1}$, subsequently get diluted by distilled water to $500 \mathrm{mg} \cdot \mathrm{L}^{-1}$. 
The adsorbent pellets in the amount of $500 \mathrm{mg}$ were placed into $100 \mathrm{ml}$ sludge solution. Approximately $3 \mathrm{ml}$ of sludge samples were taken and labeled into a glass bottle $0,5,10,15,20,30,40$ and 60 minutes before being sent to concentration measurement.

\section{Effect of $\mathrm{pH}$}

The $\mathrm{pH}$ of adsorption was varied to 3.66 , 7.28, and 10.08. A temperature control water bath stirrer was used at $30^{\circ} \mathrm{C}$. The stirring speed was set to $50 \mathrm{rpm}$, and initial adsorbate concentration was measured under sludge initial condition by XRF. The adsorbent pellets in the amount of 500 mg were placed into $100 \mathrm{ml}$ sludge solution of different $\mathrm{pH}$. The adsorption was performed for 30 minutes. All three samples of sludge undergoing adsorption at different temperatures were collected and labeled before being sent to the concentration measurement of heavy metals.

\section{Effect of temperature}

In orde to study the effect of temperature on the adsorption process, the temperature during adsorption was varied from 30 and $70^{\circ} \mathrm{C}$. Hence, a temperature control water bath stirrer was used. The sludge solution $\mathrm{pH}$ was set to 7.28 , stirring speed $-50 \mathrm{rpm}$, and the initial adsorbate concentration was measured under sludge initial condition by XRF. The adsorbent pellets in the amount of $500 \mathrm{mg}$ were placed into a $100 \mathrm{ml}$ sludge solution once the desired temperature was reached. The adsorption was performed for 10 minutes. The two samples of sludge undergoing adsorption at different temperature were collected and labeled before being sent to concentration measurement of heavy metals.

\section{RESULTS AND DISCUSSION}

\section{Sludge solution characterization}

The sludge obtained from Sungai Selangor Phase 2 (SSP2), claimed to have high heavy metals content, was analyzed using X-Ray Fluorescence. The elements are presented together with their respective fraction in Figure 1.

\section{Adsorbent characterization}

It was observed that the major constituents in the sewage sludge specifically obtained from Sungai Selangor Phase 2 are silicon, aluminum, iron, potassium, phosphorus, titanium, and calcium with the percentage of $43 \%, 24.5 \%$, $19.9 \%, 6.45 \%, 1.86 \%, 1.67 \%$, and $1.07 \%$, respectively. Silicon is mostly found in the sand; hence, it is the major constituent in the sludge accumulated during the settling in the wastewater treatment process. A large quantity of silica was found in the sludge due to the the water being sourced from a river. On the other hand, the presence of the high amount of aluminum and iron is due to its usage as flocculation agents in the secondary treatment process causing it to accumulate in the settled sludge. Heavy metals such as iron, titanium, manganese, zinc, arsenic, copper, nickel, chromium and zirconium are present in the sludge with concentration

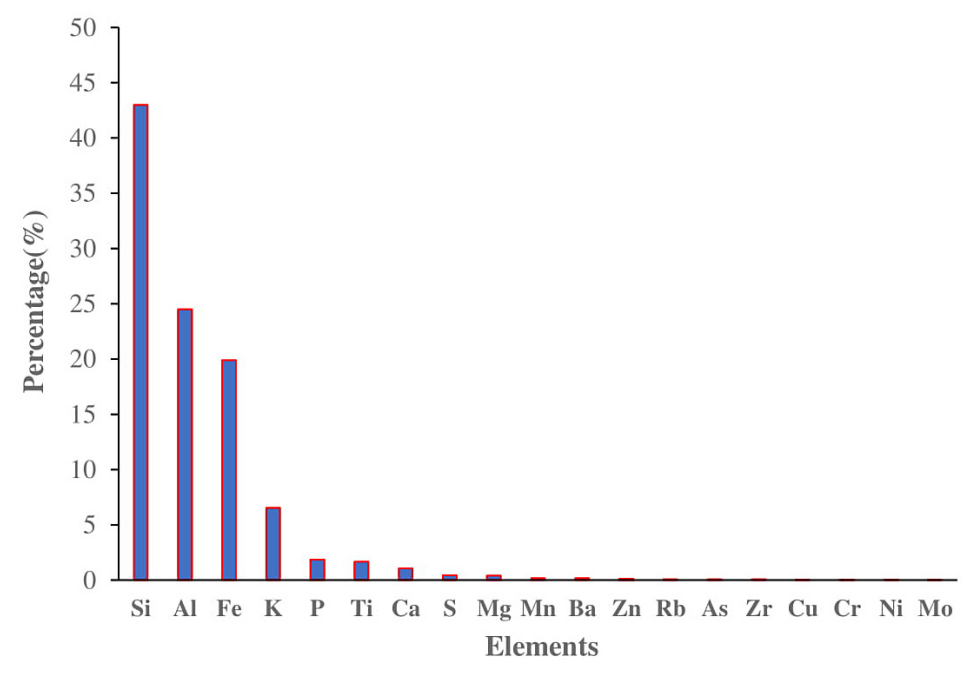

Figure 1. SSP2 sludge content 
ranging from $30 \mathrm{ppm}$ to $150 \mathrm{ppm}$ [Hasfalina et al. 2012]. In the current practice, these constituents are disposed of to the landfill, therefore leading to the unanticipated accumulation of heavy metals in the soil. In a nutshell, Selangor is a heavy industrial and manufacturing area in Malaysia; hence, it is expected that its wastewater contains a high amount of metals. When it undergoes wastewater treatment, the metal element will be accumulated in the disposed sludge [Chowdhury et al. 2012].

\section{SAP characteristics}

The surface area and pore analysis are carried out under nitrogen adsorption isotherm at $77 \mathrm{~K}$. All calculations were performed by the system software. The result obtained is presented in table 4.1, together with the result comparison obtained from the literature review.

From Table 1, the BET surface area of the prepared KFAC was found to be $264.94 \mathrm{~m}^{2} \cdot \mathrm{g}^{-1}$ with a cumulative adsorption surface area of $25.77 \mathrm{~m}^{2} \cdot \mathrm{g}^{-1}$ only. The BET surface area is lower than those observed in the KFAC developed by Chowdhury [2013] using the same method and activation parameters. This might due to the different materials handling, as well as the different characteristics of the initial sample collected. However, the cumulative adsorption area was found to be very low, which is around $10 \%$ of the BET surface area, giving a sharp difference with the KFAC obtained by Chowdhury in which the adsorption area is around 50 to $90 \%$ of its BET surface area [Chowdhury 2013].

Another BET surface area of the KFAC was developed from another research utilizing different preparation steps, for instance, those developed by Shamsuddin et al. [2016], who employed a similar method but different activation parameters and agents, obtaining slightly higher BET area, while the size of its micropores is approximately the same as obtained in this experiment. Another research utilizing only chemical activation with alkali solution produces a very low BET surface area, as compared to those using the physiochemical activation. Comparing the BET surface area of the KFAC obtained, it amounted to about half and/or one-third of the commercial activated carbon BET surface area, such as lignite, F100, BPL from Calgon, US and BDH from Merck, the BET surface areas of which were reported to be 600-650, 957, 972 and $1118 \mathrm{~m}^{2} \mathrm{~g}^{-1}$, respectively [Sajab et al. 2010].

High BET surface area facilitates more adsorption; hence, higher BET surface of the prepared adsorbent is favorable. The pore size distribution, however, does not have uniform favored specification. It all depends on each application, where the adsorbent is utilized, for instance, in the application of large constituent capture, high micropores distribution would result in poor adsorption as it fails to capture large constituent, whereas the high distribution of macro and mesopores would give poor adsorption performance for small constituent capture as it is unable to retain them permanently [Mahmoud et al. 2012].

The micropore's surface area, micropores volume, mesopores volume and average pore diameter of the prepared adsorbent are 210.67 $\mathrm{m}^{2} \cdot \mathrm{g}^{-1}, 0.1072 \mathrm{~cm}^{3} \cdot \mathrm{g}^{-1}, 0.0707 \mathrm{~cm}^{3} \cdot \mathrm{g}^{-1}$, and 8.169 $\mathrm{nm}$, respectively. The values are still lower than those found in the KFAC developed by Chowdhury, but not too significant. The average pore diameter, however, is almost four times higher which implicates that the adsorbent has many mesopores and macrospores as compared to the

Table 1. Surface area and pore characteristic of the prepared adsorbent, reference adsorbent

\begin{tabular}{|c|c|c|c|c|c|c|c|c|c|}
\hline Material & $\begin{array}{l}\text { Type of } \\
\text { activated } \\
\text { carbon }\end{array}$ & $\begin{array}{c}\text { BET } \\
\text { Surface } \\
\text { area } \\
\left(\mathrm{m}^{2} \cdot \mathrm{g}^{-1}\right)\end{array}$ & $\begin{array}{c}\text { Cumulative } \\
\text { adsorption } \\
\text { area } \\
\left(\mathrm{m}^{2} \cdot \mathrm{g}^{-1}\right)\end{array}$ & $\begin{array}{c}\text { Micropore } \\
\text { surface area } \\
\qquad\left(\mathrm{m}^{2} \cdot \mathrm{g}^{-1}\right)\end{array}$ & $\begin{array}{c}\text { Meso pore } \\
\text { Surface area } \\
\qquad\left(\mathrm{m}^{2} \cdot \mathrm{g}^{-1}\right)\end{array}$ & $\begin{array}{l}\text { Micropore } \\
\text { Volume } \\
\left(\mathrm{cm}^{3} \cdot \mathrm{g}^{-1}\right)\end{array}$ & $\begin{array}{l}\text { Mesopore } \\
\text { Volume } \\
\left(\mathrm{cm}^{3} \cdot \mathrm{g}^{-1}\right)\end{array}$ & $\begin{array}{c}\text { Pore } \\
\text { diameter } \\
(\mathrm{nm})\end{array}$ & Ref. \\
\hline \multirow{7}{*}{ Kenaf } & KFAC & 264.94 & 25.77 & 210.67 & 54.274 & 0.1072 & 0.0707 & 8.17 & $\begin{array}{l}\text { This } \\
\text { study }\end{array}$ \\
\hline & KFAC (Pb) & 525.50 & 504.10 & 610.23 & - & 0.2169 & 0.1051 & 2.49 & [21] \\
\hline & KFAC (Cu) & 330.40 & 178.33 & 361.30 & - & 0.1350 & 0.0540 & 2.29 & [7] \\
\hline & KFAC (Mn) & 386.03 & 219.80 & 278.60 & - & 0.1605 & 0.0725 & 2.41 & [21] \\
\hline & KFAC & 299.02 & - & 229.20 & - & 0.1200 & - & - & [21] \\
\hline & KFAC & 5.44 & - & - & - & - & - & - & [16] \\
\hline & KFAC & 289.50 & - & - & - & - & - & - & [6] \\
\hline
\end{tabular}


micropores. This explains the lower surface area obtained in the developed KFAC in this experiment, as micropores are characterized by large surface area but a lower fraction of pore volume compared to mesopores [Shamsudin et al. 2015]. The activated adsorbents prepared in this study have average pore diameters larger than 0.22 $\mathrm{nm}$; hence, the developed activated adsorbents in this experiment are in the mesopore region according to the IUPAC classification [Martin et al. 2009]. The formation of micropores in activated carbon or biochar is due to the presence of lignin in the precursor. Therefore, a large proportion of lignin will contribute to the formation of microporous activated carbon. Other important factors that strongly affect the pore formation and distribution are the preparation and activation parameters [Ahmedna et al. 2000]. For instance, the semi-carbonization step is important to disrupt the cellulosic backbone to facilitate diffusion of the activating agents, both $\mathrm{CO}_{2}$ and $\mathrm{KOH}$, which increase the reaction between the activation agents and carbon matrix that leads to the formation of pores within the carbon matrix, thereby improving the BET surface area and pore volumes [Chowdhury et al. 2012]. However, the wall between micropores presents inside the carbon matrix can also burn to a certain extent due to the presence of heat during the physical activation, causing it to combine with another micropore nearby, forming larger pores called mesopores. The presence of mesopores provides ways for the adsorbate to enter smaller pores and remain there. An adsorbent needs to have enough distribution of all pores in its particle-matrix since all these pores have their role in the adsorption process. The ratio of the $\mathrm{KOH}$ addition determines the micropores formation while the amount of heat and time given during physical activation will determine the degree of burn within the adsorbent matrix, hence contributing to the formation of all micropores, mesopores, and macropores. The selection of the activation gas is also important, as it gives sufficient control over the process; for some gases, it reacts easily with certain materials, making it hard to control the reaction (sometimes overburning) and ensure proper pore distribution. Overall, the activated adsorbent prepared in this study showed the characteristics which are comparable with other adsorbent derived from the same biomass as well as the commercial activated carbon available in the market.

\section{Morphological and elemental characterization}

\section{Morphological analysis}

The surface morphology of the Kenaf fiber $(\mathrm{KF})$ precursors together with its respective char (KFC) and activated carbon (KFAC) were examined using field emission scanning electron microscopy (FESEM). The results obtained include the micrographs of KF, KFC, and KFAC by which the morphology of the surfaces is observed, and EDX in which the spectrum of each element contained on the surface is obtained together with elements mapping. It is shown in Figure 2.

From the FESEM micrographs obtained, the change in surface texture and pore development is visible. Plates 2(a-d) show the FESEM micrographs of the KF precursor, semi carbonized char of KF, and the KFAC prepared for heavy metals adsorption, respectively. As observed from FESEM micrographs of the precursors, Plate 2(a), the surface textures of KF precursors are rough and uneven, with some minor small and large pores observed on its surface. After the semi carbonization process, the surface becomes rougher and some large pores and new smaller pores are developed and found on the surfaces of the chars, as shown in Plate 2(b). However, it is still not that porous. The pores formed after the semi carbonization process are narrow, irregular and even some may be tapered by tarry substances deposition, as discussed earlier. The picture shows that semi carbonization alone does not create enough porosities. This is due to the incomplete decomposition of organic constituents present in the carbonaceous precursors which in that case, the residues of carbonization products are more than able to block the resulted pores [13].

After the physical and chemical activation, the activated carbons produced from KF have a spherical-shaped particle and demonstrate a highly porous surface all over its sides as seen in Plate 2(c). The non-homogenous mesopores and macrospores distribution with random pores arrangement are seen in the picture. The pores observed on the surface of KFAC can facilitate the transfer of adsorbates (heavy metals) into the inner part of the adsorbent particle and retain there, depending on the size of the adsorbate particles relative to the surface pores size.

From Plate 2(d), it is observed that the pores available on the surfaces of the activated carbons prepared from KF are well pronounced with 


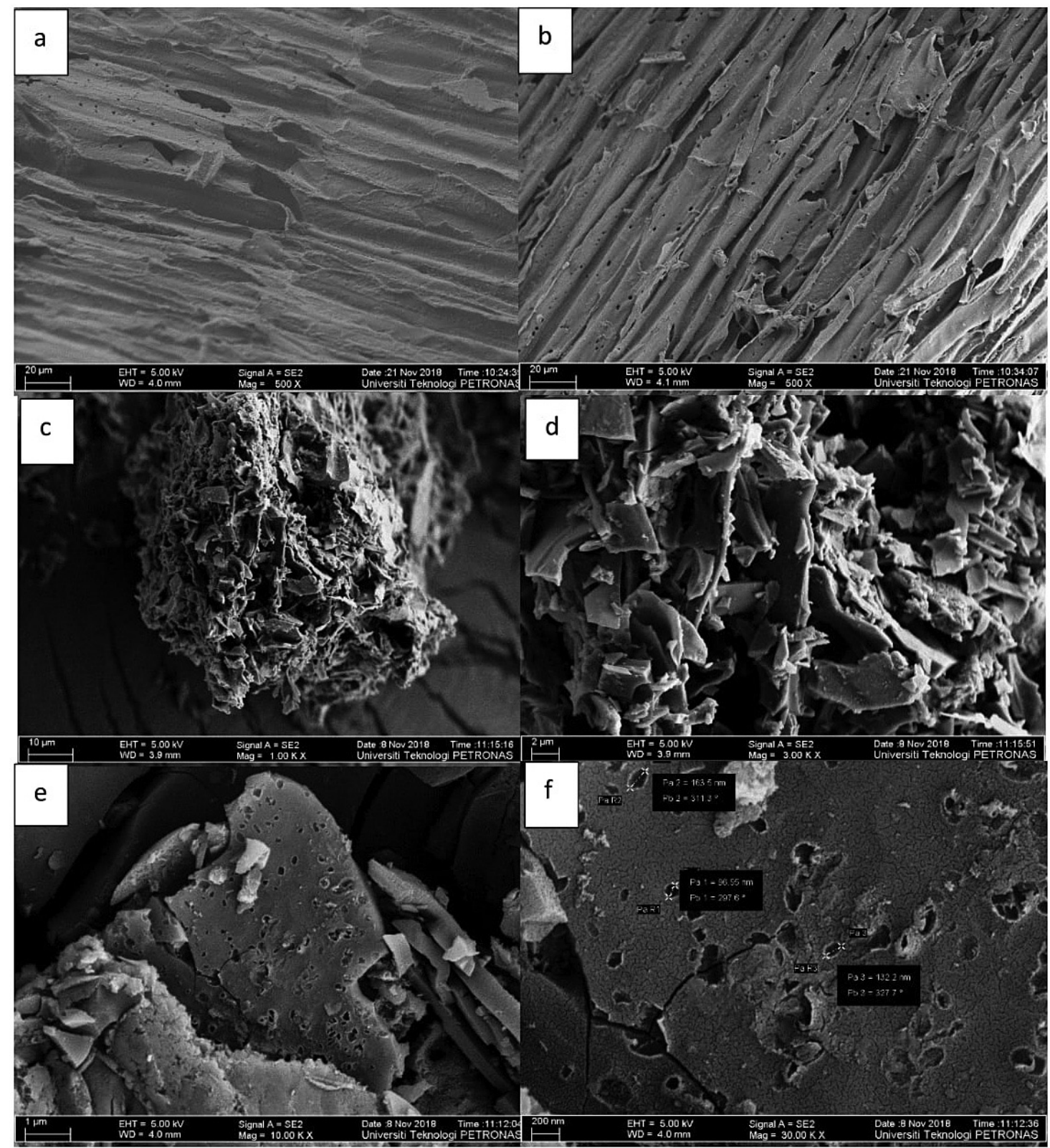

Figure 2. FESEM Micrographs $(\times 500)$ of (a) Raw Kenaf Fibre (b) Semi Carbonized KF (c) KF Activated Carbon (d) $(\times 3000)$ KF Activated Carbon. $(e)(\times 10000)$ KF Activated Carbon $(f)(\times 30000)$ KF Activated Carbon

distinct pore walls. They are randomly arranged in the spherical-shaped adsorbent particle. Besides, the matters that are blocking the pores observed in the chars disappeared, indicating that they were removed through gasification during the activation process. Thus, they are carried away with the exhaust gas leaving most of the pores clear and easily absorbable by the cations. From Plate 2(a) and (b), at a magnification of 10000x and 30000x, the micropores are observed in the KFAC. Micropores shown are randomly distributed. In summary, $\mathrm{KOH}$ and $\mathrm{CO}_{2}$ are effective in creating well-developed pores on the precursors surface, resulting in the activated carbons having large pore volume and surface areas, provided that correct activation conditions are implemented.

\section{Elemental analysis}

In this section, the analysis of the element presents in KF, semi carbonized KF, KFAC before adsorption and KFAC after adsorption was carried out qualitatively and quantitatively. The qualitative analysis of the element present in the KFAC was carried out using FESEM (mapping and EDX). The elements spectrums were observed, together with their mapping on the adsorbent layers. The quantitative analysis was carried out using X-Ray Fluorescence. The results of the 
qualitative analysis are shown in the spectrum graph in Figures 3, 4, 5 and 6.

Figure 3 shows that the peaks observed are in between 0 to $4 \mathrm{keV}$. The magnitude of the peak indicates higher intensity exhibited by the element, implying higher domination of the element contained in the particle. At $0.2 \mathrm{keV}$, two peaks are identified overlapping with each other. The peaks are among the highest ones exhibited by
$\mathrm{Cl}$ and $\mathrm{C}$, followed by two peaks at $0.4 \mathrm{keV}$ and $0.6 \mathrm{keV}$ that belong to $\mathrm{K}$ and $\mathrm{O}$ respectively. The following peaks that belong to $\mathrm{Al}, \mathrm{Cl}$, and $\mathrm{K}$ are found at $1.5 \mathrm{keV}, 2.6 \mathrm{keV}$ and $3.4 \mathrm{keV}$, respectively. Hence, five elements present in the raw $\mathrm{KF}$ include $\mathrm{C}, \mathrm{Cl}, \mathrm{K}, \mathrm{O}$, and $\mathrm{Al}$.

The spectrum of the pyrolyzed Kenaf is shown in Figure 4. The exhibited peaks are the same as what was obtained in raw Kenaf. However, $\mathrm{Cl}$

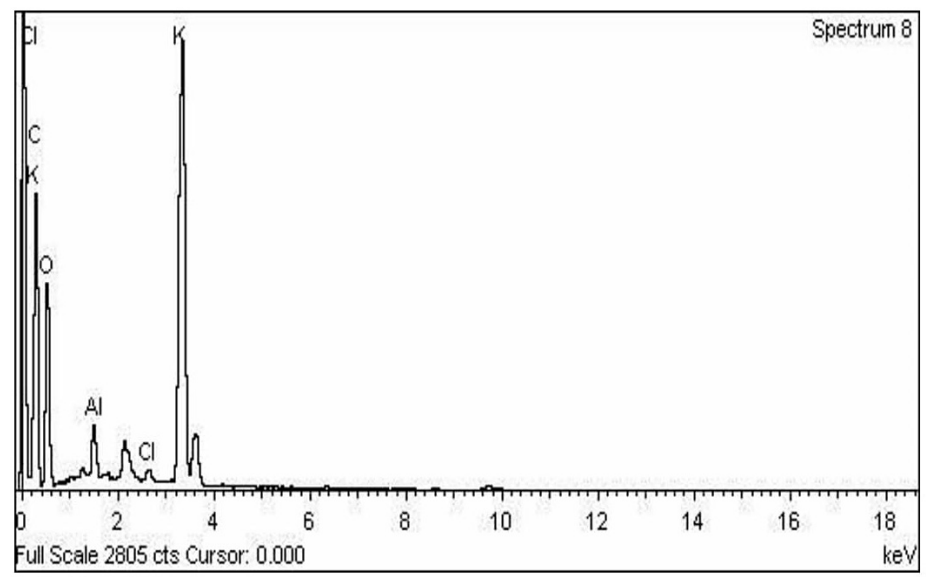

Figure 3. EDX result of the raw Kenaf Fiber

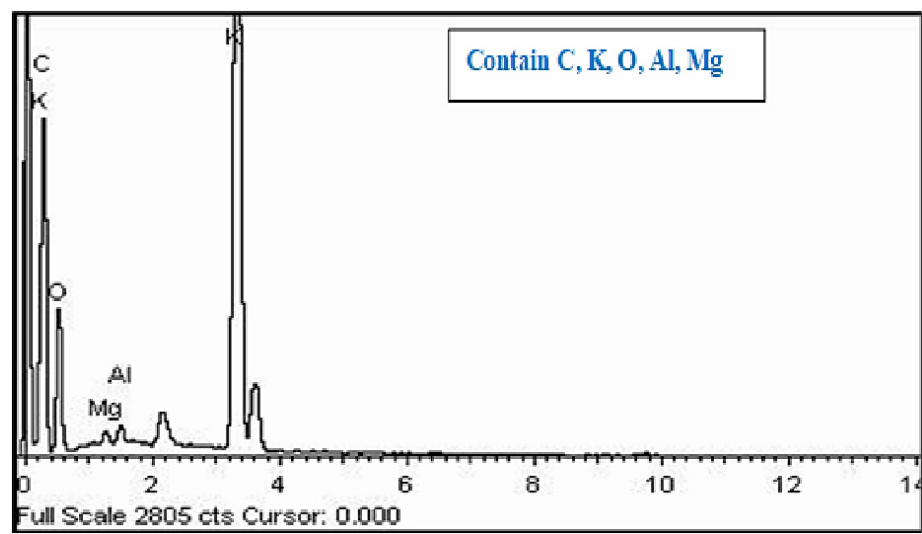

Figure 4. EDX result of semi carbonized Kenaf Fiber

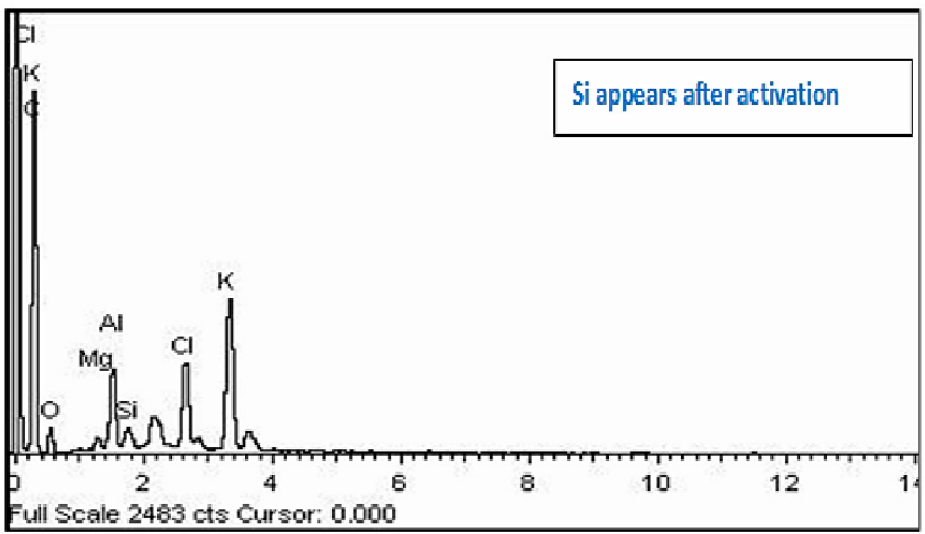

Figure 5. EDX result of Kenaf Fiber Activated Carbon before adsorption. 
is no longer present in the substance. Instead, the $\mathrm{Mg}$ peak is observed at $1.2 \mathrm{keV}$. That leaves around five elements present in the pyrolyzed Kenaf, including $\mathrm{C}, \mathrm{K}, \mathrm{O}, \mathrm{Al}$ and $\mathrm{Mg}$, where $\mathrm{C}$ and $\mathrm{K}$ are still the dominant elements.

After the chemical and physical activation, some new elements were observed in the spectrum shown in Figure 5. That includes $\mathrm{Cl}$, which disappeared after the carbonization process and $\mathrm{Si}$ element which is observed at $1.8 \mathrm{keV}$. The return of the $\mathrm{Cl}$ present in activated carbon is due to the addition of $\mathrm{KOH}$ as an activating agent, as well as $\mathrm{HCl}$ and $\mathrm{NaOH}$ as the neutralizing agent during the washing process of the resultant activated carbon. The chloride comes from the salt generated throughout the neutralizing (washing) process. The Si content, however, is suspected to come from the ash, which is partially formed during the physical activation process (heating up to approximately $584.3^{\circ} \mathrm{C}$ for about 1.6 hours). The rest of the elements are those identified earlier in the semi carbonized $\mathrm{KF}$ such as $\mathrm{C}, \mathrm{K}, \mathrm{O}, \mathrm{Al}$, and $\mathrm{Mg}$.
After the adsorption process, some heavy metals are absorbed by KFAC; hence, it is expected that the spectrum of KFAC after adsorption will have many peaks, as compared to the previous three samples, due to the presence of heavy metals in the adsorbent. As observed from Figure 6, peaks range from $0 \mathrm{keV}$ to $6 \mathrm{keV}$, with a total of 13 elements identified. The major constituents are still carbon and potassium observed at $0.1 \mathrm{keV}$ as well as the elements identified earlier, such as $\mathrm{Cl}, \mathrm{O}, \mathrm{Mg}, \mathrm{Si}$, and $\mathrm{Al}$. The rest of the elements observed are $\mathrm{Mn}, \mathrm{Si}, \mathrm{Ca}, \mathrm{Fe}, \mathrm{As}$, and $\mathrm{Ba}$, indicating that these elements are being adsorbed by Kenaf during the adsorption experiment.

On the other hand, the quantitative analysis of the element of KF, semi-carbonized KF and KFAC was carried out using XRF. The raw result is displayed in Table 2. In the table, it is shown that the main elements present in Kenaf and processed Kenaf are carbon and oxygen. The element present in the adsorbent from which it is processed, until it becomes an activated carbon is shown in the diagrams in Figure 6.

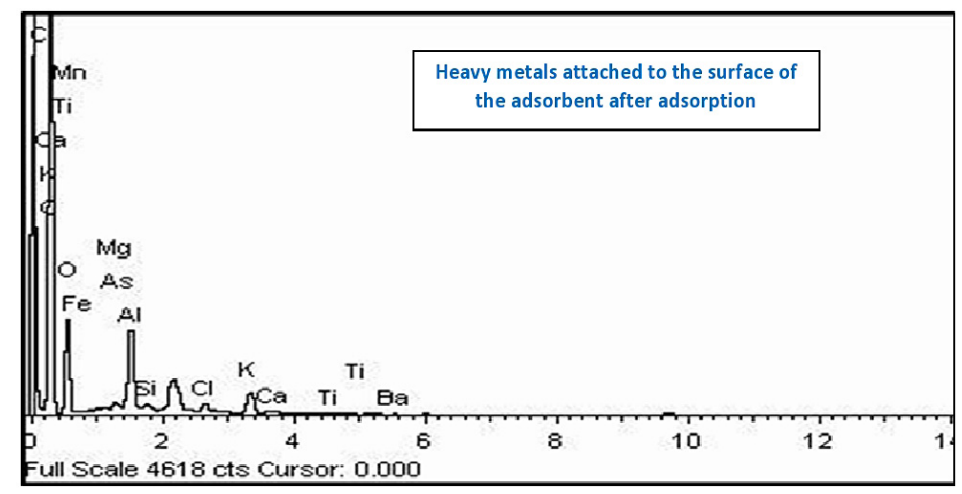

Figure 6. EDX result of Kenaf Fibre Activated Carbon after adsorption

Table 2. The weight percentage of elements in KF, semi-carbonized KF and KFAC

\begin{tabular}{|c|c|c|c|c|}
\hline \multirow{2}{*}{ Element } & \multicolumn{4}{|c|}{ wt. \% } \\
\cline { 2 - 5 } & Raw kenaf & Pyrolyzed kenaf & KFAC BT & 41.28 \\
\hline $\mathrm{C}$ & 40.20 & 41.50 & 75.94 & 43.05 \\
\hline $\mathrm{O}$ & 41.95 & 35.5 & 9.93 & 12.16 \\
\hline $\mathrm{Al}$ & 1.21 & 0.37 & 2.21 & 0.27 \\
\hline $\mathrm{Cl}$ & 0.35 & 0.41 & 3.5 & 1.83 \\
\hline $\mathrm{K}$ & 16.26 & 22.23 & 7.49 & 0.36 \\
\hline $\mathrm{Si}$ & - & - & 0.57 & 0.41 \\
\hline $\mathrm{Mg}$ & - & - & 0.36 & 0.15 \\
\hline $\mathrm{Ca}$ & - & - & - & 0.22 \\
\hline $\mathrm{Fe}$ & - & - & - & 0.55 \\
\hline $\mathrm{P}$ & - & - & - & 0.36 \\
\hline $\mathrm{Ni}$ & - & - & - & 0.12 \\
\hline $\mathrm{Zn}$ & - & - & - & 0.14 \\
\hline $\mathrm{Ti}$ & - & - & - & 0.02 \\
\hline $\mathrm{Mn}$ & - & - & - & 0.12 \\
\hline $\mathrm{Cu}$ & & & & - \\
\hline
\end{tabular}


Table 2 shows the percentage of the carbon, oxygen and potassium content contained in the samples. As observed in Table 2, the carbon content is slightly increased after pyrolysis from the initial value of $40.2 \%$ to $41.5 \%$. This is due to more carbon being formed during the carbonization process. The content is then rapidly increased after the physiochemical activation to approximately $75.9 \mathrm{wt} . \%$. The increase of the carbon content during the activation is due to the second heating under $\mathrm{CO}_{2}$, as the activation agent during physical activation. After the adsorption analysis, the percentage is reduced due to the addition of the elements adsorbed by the adsorbent (weight remain constant while the total weight is increased). It was also observed that the oxygen element weight percentage is decreasing from $42 \%$ initially in raw Kenaf to $35.5 \%$ in pyrolyzed Kenaf and $9.9 \%$ in the activated carbon, as carbon becomes the dominant element at this stage.

As for potassium, its percentage is slightly increased after pyrolysis due to the potassium formation during the process and immediately decrease after activation. This may due to the rapid increase in carbon, while potassium remains the same. The percentage keeps decreasing after the adsorption test is performed. This is due to greater element addition to the Kenaf adsorption while the potassium content remains the same. Nevertheless, these three elements are the major constituents of the raw Kenaf, semi-carbonized Kenaf and KFAC.

Figure 7 shows that the chloride content is increased after the adsorbent activation is performed. The main cause is the addition of $\mathrm{KOH}$ as an activating agent, as well as $\mathrm{HCl}$ and $\mathrm{NaOH}$ as the neutralizing agent during the washing process of the resultant activated carbon. The chloride comes from the salt generated throughout the neutralizing (washing) process. The presence of the Si content, which previously was absent in the raw, as well as carbonized Kenaf fiber, is derived from the ash which is partially formed during the physical activation process.

It is also observed from Table 3 that the aluminum content is increased Trom $2.21 \%$ in KFAC before adsorption to $12.6 \%$ after adsorption. Hence, the increase of aluminum is caused by the adsorption of aluminum from the sludge to the Kenaf adsorbent. The heavy metals are present in neither raw nor semi-carbonized KF. However, its traces are found in the KFAC after the adsorption test is performed. Hence, it can be concluded that the heavy metals from the sludge are being captured by the KFAC developed in this experiment.

\section{Batch adsorption study}

\section{Effect of contact time}

Batch equilibrium experiments are performed by using $100 \mathrm{ml}$ of sludge solution from SSP2 containing $\mathrm{Fe}, \mathrm{Ti}, \mathrm{Mn}, \mathrm{Zn}, \mathrm{As}, \mathrm{Cu}, \mathrm{Ni}, \mathrm{Zr}$ and Ga having pre-determined initial concentrations using XRF, with an equivalent adsorbent mass of $0.5 \mathrm{~g}$ of the prepared KFAC. Figure 7 illustrates the adsorption uptake of various heavy metals (Fe, Ti, $\mathrm{Mn}, \mathrm{Zn}, \mathrm{As}, \mathrm{Cu}, \mathrm{Ni}, \mathrm{Zr}$, and $\mathrm{Ga}$ ) against contact time, $\mathrm{t}$ (minutes) onto KFAC at $\mathrm{pH} 7.28$ and temperature of $30^{\circ} \mathrm{C}$.

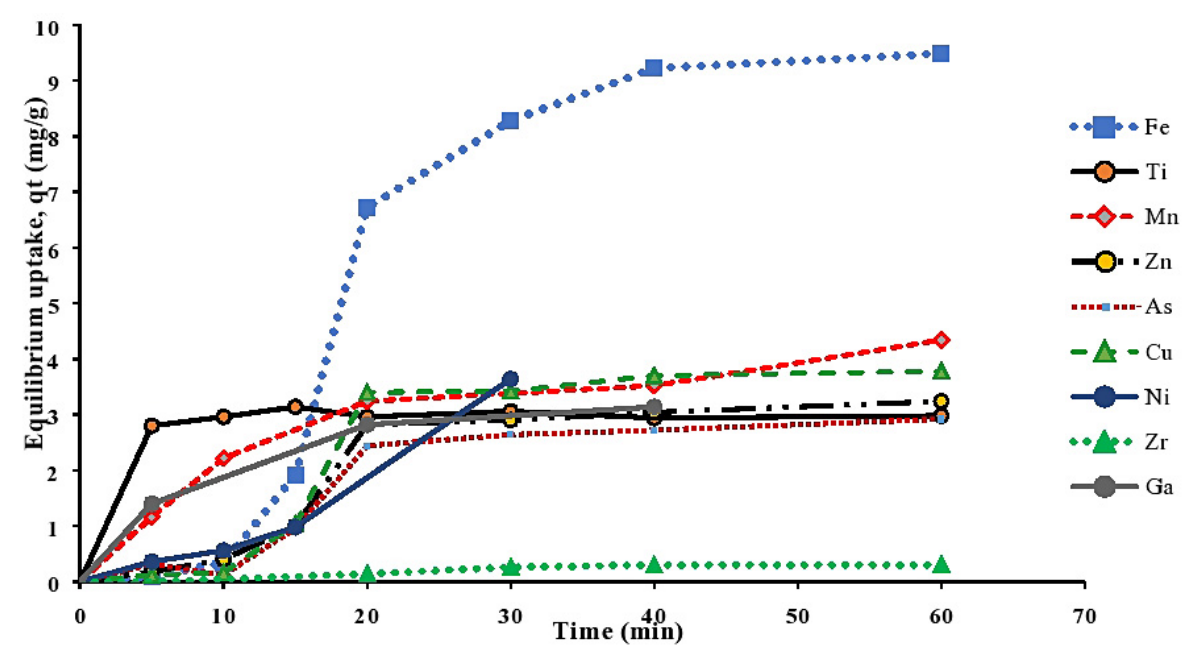

Figure 7. Effect of contact time to the equilibrium uptake of various heavy metals (Fe, Ti, Mn, Zn, As, Cu, Ni, Zr, and Ga) onto KFAC 
From the plot observed, for all heavy metals elements adsorbed onto KFAC, the amount of equilibrium uptake (qt) is increased with time. However, the equilibrium uptake will eventually reach a maximum value at a certain point after which the equilibrium uptake will remain constant. The point in which the amount of solute being removed is no more significant is called an equilibrium point. The amount adsorbate adsorbed at the equilibrium time reflects the adsorbent maximum capacity at that certain adsorption condition. Two distinct regions of sorption are shown in the plot obtained. In the initial region, the adsorption uptake is fast and rapid. For instance, for Iron ( $\mathrm{Fe})$ shown in the figure, the adsorption uptake is increased from 0 to $6.9 \mathrm{mg} / \mathrm{L}$ in the first 20 minutes and becomes slower onwards. In the curve, it is shown as the steeper region. The second stage is identified as a curve that is almost parallel to the $\mathrm{x}$-axis. In the second stage, the equilibrium uptake becomes slower than that in the first stage. This can be taken as an indication that adsorption has almost reached equilibrium and that the adsorbent has almost reached its maximum capacity. This mechanism is as explained by Chowdhury [2013] who states that at an initial stage, the rapid uptake is due to a lot of vacant sites on the surface of the adsorbent, and after a lapse of time, some of the active surface sites will be occupied by the substances retained in the adsorbent; hence, it becomes difficult for the remaining adsorbate to occupy a site on the adsorbent surface.

For KFAC, all the concentrations reached equilibrium within 40 to 60 minutes. In the case of $\mathrm{Fe}$, approximately 60 minutes and more are required by KFAC to reach the equilibrium uptake of $9.5 \mathrm{mg} / \mathrm{g}$. For Ti, approximately 40 to $60 \mathrm{~min}-$ utes is required by KFAC to reach the equilibrium uptake of $2.98 \mathrm{mg} / \mathrm{g}$. For $\mathrm{Mn}$, the equilibrium has not been reached after the experiment time limit passed. Hence, it requires more than one hour for KFAC to reach the equilibrium adsorption for $\mathrm{Mn}$. In the case of $\mathrm{Zn}$ and $\mathrm{Cu}$, approximately 40 to 60 minutes is required by KFAC to reach the equilibrium uptake of $3.2 \mathrm{mg} / \mathrm{g}$ and $3.8 \mathrm{mg} / \mathrm{g}$ respectively. In the case of As and $\mathrm{Zr}$, equilibrium is reached after 30 minutes with the equilibrium uptake of approximately $3 \mathrm{mg} / \mathrm{g}$. It is also observed that about $22.97 \%, 14.2 \%, 28.37 \%, 30.28 \%, 31.60 \%$, $31.40 \%, 32.10 \%, 5.07 \%$, and $31.80 \%$ of $\mathrm{Fe}$, Ti, $\mathrm{Mn}, \mathrm{Zn}, \mathrm{As}, \mathrm{Cu}, \mathrm{Ni}, \mathrm{Zr}$, and $\mathrm{Ga}$ are removed by $\mathrm{KFAC}$, respectively, from $100 \mathrm{ml}$ sludge solution.
The average removal percentage of all types of heavy metals species is $30 \%$ except that for Titanium and Zirconium. The removal percentage is strongly dependent on the characteristic of the metals (for instance its size) relative to the adsorbent pores size. An adsorbate of greater size will not be adsorbed in the adsorbent having very small pores size, while on the contrary, the larger size of pores will not be able to retain adsorbate with small particle size.

Generally, the adsorption performance varies with the category and physio-chemical properties of the adsorbent and adsorbate used. In this study, KFAC showed the highest equilibrium uptake and removal percentage towards Iron, followed by $\mathrm{Mn}, \mathrm{Cu}, \mathrm{Ga}, \mathrm{Ti}, \mathrm{As}$, and $\mathrm{Zr}$. The relatively high adsorption uptakes of KFAC are due to its relatively high surface areas and pore volumes investigated earlier. Besides the physical characteristics, the adsorption performance of an activated adsorbent is also influenced by its surface chemistry.

\section{Effect of $\mathrm{pH}$}

The $\mathrm{pH}$ of the aqueous solution is thought to play an essential role inside the adsorption system, affecting the character of each ion to be removed and the adsorbents itself [Ghorpade et al. 2017]. There is a competition between metal cations and the protons present in the acidic solution at the adsorption system. The adsorption phenomena disappear and change to precipitation when the pHs tend to more than 7 (usually $\mathrm{pH}$ >7). The effect of the initial $\mathrm{pH}$ on the removal of metals was studied for a $\mathrm{pH}$ range of 3-11 and the results are presented in Figure 8. It can be observed that for six metals, namely $\mathrm{Fe}, \mathrm{Mn}, \mathrm{Zn}$, $\mathrm{As}, \mathrm{Cu}$ and $\mathrm{Ni}$, removal increased along with an increase in the initial $\mathrm{pH}$ to neutral $(\mathrm{pH}=7)$, then the removal of those heavy metal started to decrease as $\mathrm{pH}$ increased to alkaline (>7.0). It can be observed that for the Ga removal, the acidic solution showed good removal of gallium, but the optimum result was at neutral $\mathrm{pH}$ then showed poor removal of gallium in the alkaline solution. For the zirconium removal, it found that the optimum value of $\mathrm{pH}$ is 11 while the titanium removal was high when the $\mathrm{pH}$ solution was at 7 $\mathrm{pH}$ then there was no effect of $\mathrm{pH}$ on titanium removal. The results were similar to those found by Igberase [2014], Asadi [2008] (Zn(II): modified rice hull and sawdust and Chen et al. 2011]. The pattern of metal adsorption in this study was 
consistent with Gautam that a high percentage of metal ion removal would normally occur at a $\mathrm{pH}$ close to neutral [Gautam et al. 2014]. This $\mathrm{pH}$ value will be different for different metals, based on their solubility. This shows that the adsorptive process will occur in a well-defined $\mathrm{pH}$ range. In general, under optimum $\mathrm{pH}$ conditions, the adsorbent and the $\mathrm{pH}$ should have opposite charges for enhanced adsorptive interactions.

\section{Effect of temperature}

In order to study the effect of initial temperature on the removal percentage of $\mathrm{Fe}, \mathrm{Ti}, \mathrm{Mn}, \mathrm{Zn}$, $\mathrm{As}, \mathrm{Cu}, \mathrm{Ni}, \mathrm{Zr}$, and $\mathrm{Ga}$ onto the prepared activated adsorbent KFAC, the solution temperature was adjusted to room temperature and higher temperature at $70^{\circ} \mathrm{C}$, while other parameters such as $\mathrm{pH}$ and contact time were kept constant at 7 and 10 minutes, respectively. The initial concentrations of the investigated elements were investigated using XRF. The graph of the effect of temperature for each element was then plotted and shown in Figure 9.

On the basis of Figure 9, it is observed that all heavy metals showed the same trend, i.e. the removal of all heavy metals onto KFAC is higher when the temperature is higher than $30^{\circ} \mathrm{C}$ or approximately $70^{\circ} \mathrm{C}$, except As which shows better removal at a lower temperature. The removal efficiency of the heavy metals ions from aqueous solution normally increased along with temperature and the maximum removal of most of the heavy metals was observed at $70^{\circ} \mathrm{C}$. A further increase in the temperature might not enhance the adsorption, which is similar to the study conducted by Shazia et al. [ ].

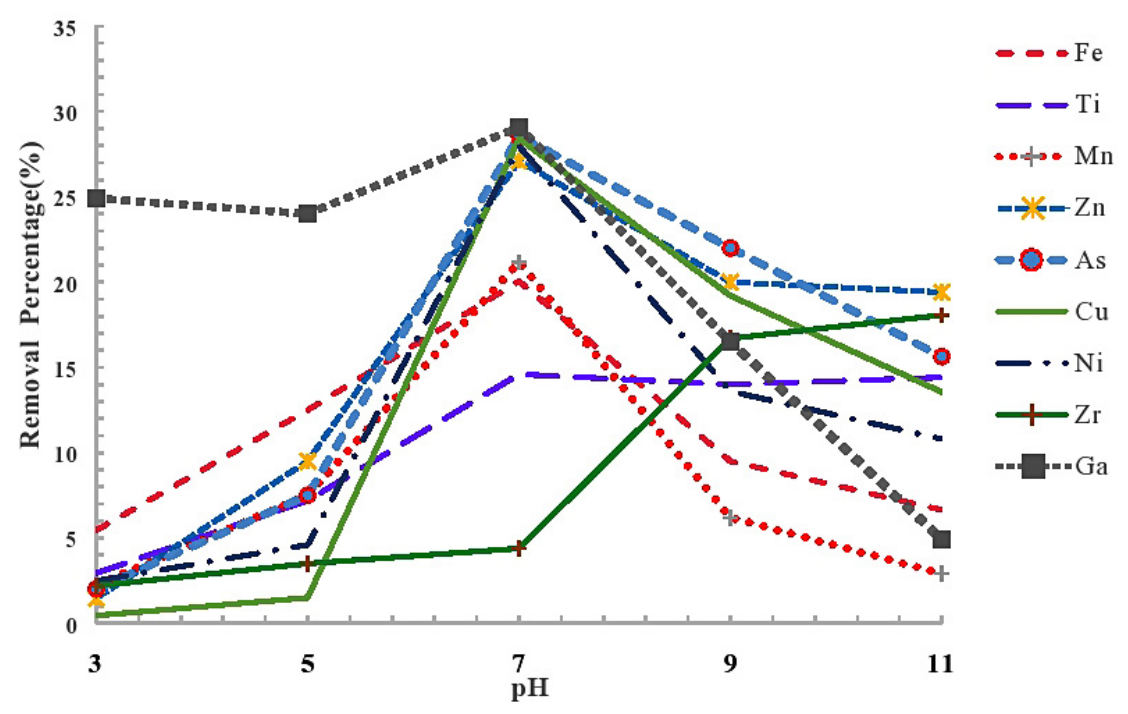

Figure 8. Effect of $\mathrm{pH}$ on the removal percentage of various heavy metals (Fe, Ti, Mn, Zn, As, Cu, Ni, Zr, and Ga) onto KFAC

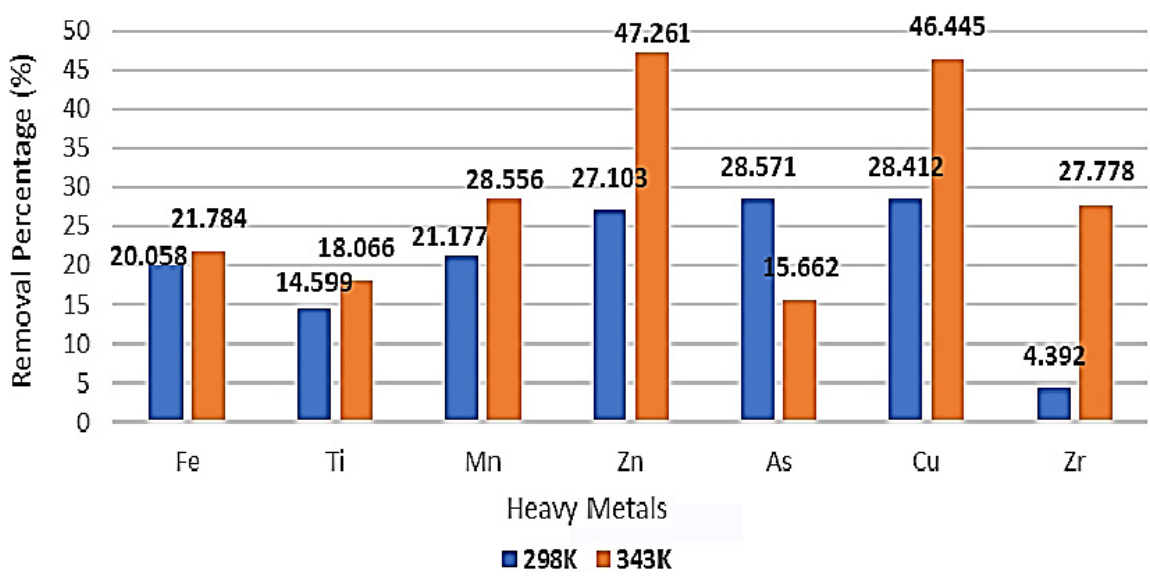

Figure 9. Effect of temperature on the removal percentage of various heavy metals (Fe, Ti, Mn, Zn, As, $\mathrm{Cu}, \mathrm{Ni}, \mathrm{Zr}$, and $\mathrm{Ga}$ ) onto KFAC 


\section{CONCLUSIONS}

The Kenaf-based activated carbon was developed based on the optimum preparation parameters. Its surface area, pore characteristic, morphology removal percentage were investigated. It was shown that the developed KFAC has a highly porous surface with mesopores dominating its surface. The surface morphology shows a clear development of pores in Kenaf from the raw state, until it becomes activated carbon. Significant pores development was identified after the physiochemical activation process. The elemental analysis showed that the carbon content increases significantly during the semi-carbonization as well as the activation process. The presence of heavy metals on the adsorbent surface after the adsorption test was also observed, indicating that the adsorbent is able to adsorb the heavy metals in the sludge.

A batch adsorption study was carried out, showing that the average removal percentage of heavy metals using Kenaf Fibre Activated Carbon in the sludge is approximately $30 \%$. The result shows that increasing the contact time will increase the equilibrium uptake of KFAC toward the heavy metals. The highest equilibrium uptake and percent removal were found in the adsorption of iron, which implicates that the developed KFAC adsorbs Fe better than other heavy metals in the sludge. The equilibrium time of KFAC towards each heavy metal element was also discussed. It was also observed that the optimum removal efficiency occured at neutral $\mathrm{pH}$ and higher temperatures. It was concluded that the Kenaf-based activated carbon can be used for the recovery of manganese from wastewater sludge through batch adsorption.

\section{Acknowledgments}

The authors would like to gratefully acknowledge Pengurusan Air Selangor for the sludge sample provided. The authors would like to thank Universiti Teknologi Petronas Malaysia for financing the project under the Ministry of high education (MOHE) with grant code FRGS- 015MA0-089.

\section{REFERENCES}

1. Ahmedna M., Marshall W.E., Rao R.M. 2000. Production of granular activated carbons from select agricultural by-products and evaluation of their physical, chemical and adsorption properties. Bioresource Technology, 71(2), 113-123.
2. Asadi F., Shariatmadari H., Mirghaffari N. 2008. Modification of rice hull and sawdust sorptive characteristics for remove heavy metals from synthetic solutions and wastewater. Journal of Hazardous Materials, 154(1-3), 451-458.

3. Chen X. et al. 2011. Adsorption of copper and zinc by biochars produced from pyrolysis of hardwood and corn straw in aqueous solution. Bioresource Technology, 102(19), 8877-8884.

4. Chowdhury Z.Z. 2013. Preparation, characterization and adsorption studies of heavy metals onto activated adsorbent materials derived from agricultural residues. Thesis (Ph.D), Universiti Malaya.

5. Chowdhury Z.Z. et al. 2012. Preparation and characterizations of activated carbon from kenaf fiber for equilibrium adsorption studies of copper from wastewater. Korean Journal of Chemical Engineering, 29(9), 1187-1195.

6. Edokpayi, J.N., Ndlovu S.S., Odiyo J.O. 2019. Characterization of pulverized Marula seed husk and its potential for the sequestration of methylene blue from aqueous solution. BMC Chemistry, 13(1), 10.

7. Everett, D.H., 1972. Manual of symbols and terminology for physicochemical quantities and units, appendix II: Definitions, terminology and symbols in colloid and surface chemistry. Pure and Applied Chemistry, 31(4), 577-638.

8. Gautam R.K. et al. 2014. Biomass-derived biosorbents for metal ions sequestration: Adsorbent modification and activation methods and adsorbent regeneration. Journal of Environmental Chemical Engineering, 2(1), 239-259.

9. Ghorpade A. et al. 2017. Water treatment sludge for removal of heavy metals from electroplating wastewater. Environmental Engineering Research, 23(1), 92-98.

10. Hasfalina C.M. et al. 2010. The potential use of kenaf as a bioadsorbent for the removal of copper and nickel from single and binary aqueous solution. Journal of Natural Fibers, 7(4), 267-275.

11. Hasfalina C.M. et al. 2012. Adsorption of copper (II) from aqueous medium in fixed-bed column by kenaf fibres. APCBEE Procedia, 3, 255-263.

12. Igberase E., Osifo P., Ofomaja A. 2014. The adsorption of copper (II) ions by polyaniline graft chitosan beads from aqueous solution: Equilibrium, kinetic and desorption studies. Journal of Environmental Chemical Engineering, 2(1), 362-369.

13. Khurshid S. et al. 2013. Adsorption study of Nymphaea alba for the removal of manganese from industrial waste water. International Journal of Physical Science, 8(45), 2052-2062.

14. Mahmoud D.K. et al. 2012. Batch adsorption of basic dye using acid treated kenaf fibre char: Equilibrium, kinetic and thermodynamic studies. Chemical Engineering Journal, 181, 449-457. 
15. Martin M.J. et al. 2003. Activated carbons developed from surplus sewage sludge for the removal of dyes from dilute aqueous solutions. Chemical Engineering Journal, 94(3), 231-239.

16. Saeed, A.A.H., Harun N.Y., Nasef M.M. 2019. Physicochemical characterization of different agricultural residues in malaysia for bio char production. International Journal of Civil Engineering and Technology (IJCIET), 10(10), 213-225.

17. Sajab M.S. et al. 2010. Removal of copper (II) ions from aqueous solution using alkali-treated kenaf core fibres. Adsorption Science \& Technology, 28(4), 377-386.

18. Saravanane R., Sundararajan T., Reddy S.S. 2002. Efficiency of chemically modified low cost adsorbents for the removal of heavy metals from waste water: A comparative study. Indian Journal of Environmental Health, 44(2), 78-87.

19. Shamsuddin M.S., Yusoff N.R.N., Sulaiman M.A. 2016. Synthesis and characterization of activated carbon produced from kenaf core fiber using $\mathrm{H} 3 \mathrm{PO} 4$ activation. Procedia Chemistry, 19, 558-565.

20. Shamsudin R., Abdullah H., Sinang S.C. 2015. Properties of oil sorbent material produced from kenaf fiber. International Journal of Environmental Science and Development, 6(7), 551-554.

21. Thitame, P.V. and Shukla S.R., 2016. Porosity development of activated carbons prepared from wild almond shells and coir pith using phosphoric acid. Chemical Engineering Communications 203(6), 791-800. 